\title{
Management of Traumatic Lumbar Meningo- radicular Injury Caused by Foreign Body Penetration using Sling Technique
}

Ko-Ting Chen ( $\nabla$ chenkoting@gmail.com )

Chang Gung Memorial Hospital Linkou Branch https://orcid.org/0000-0002-6795-5974

\section{Ying-Yun Chen}

Chang Gung Memorial Hospital Linkou Main Branch: Chang Gung Memorial Hospital

Chieh-Tsai Wu

Chang Gung Memorial Hospital Linkou Main Branch: Chang Gung Memorial Hospital

Ting-Wei Chang

Chang Gung Memorial Hospital Linkou Main Branch: Chang Gung Memorial Hospital

\section{Case report}

Keywords: duraplasty, sling procedure, traumatic spinal dural defect, ventral dural defect

Posted Date: January 19th, 2021

DOI: https://doi.org/10.21203/rs.3.rs-149180/v1

License: (a) (i) This work is licensed under a Creative Commons Attribution 4.0 International License.

Read Full License 


\section{Abstract}

\section{Background}

Non-missile penetrating spinal injuries (NMPSI) can cause delayed neural injury, including cerebrospinal fluid (CSF) leakage and spinal cord herniation, related to dural defects. To repair ventral dural defect (VDD) is particularly challenging in trauma patients and, in a meanwhile, there has been a wellestablished method: sling technique, used for patients with idiopathic spinal cord herniation (ISCH) in whom VDD being the primary pathology to deal with.

\section{Case presentation}

This 51-year-old man fell down from an altitude of six meters and landed on a plier. The neurological examination revealed decreased muscle strength (grade 3/3) in bilateral lower extremities. Computed tomography showed a pair of pliers penetrating L4 lamina, spinal canal through vertebral body, psoas muscle into retroperitoneal cavity with inferior vena cava (IVC) indentation. Emergent laparotomy revealed intact IVC with no major organ damage, and the plier was removed from back under direct visualization of IVC. Immediate posterior approach showed a through-and-through VDD. Sling technique with $\mathrm{COOK}^{\circledR}$ dura substitute was applied to cover the VDD and fixed with 7-0 prolene after neurolysis. There was no CSF leakage or nerve tissue herniation afterward. He regained working ability with full muscle strength except for a minor sequal of paresthesia of right toe.

\section{Conclusions}

In patients with NMPSI with VDD, indirect duraplasty using sling technique originally developed for treating patients with ISCH is suitable and effective in preventing CSF leakage and delayed neural injury. We further propose an algorithm emphasizing key decision makings for repairing dural defect while preventing delayed neural injury.

\section{Background}

The majority of nonmissile penetrating spinal injuries (NMPSIs) is attributed to assaults by knives involving lower cervical and upper thoracic.(1) Despite a controversial role of surgical intervention in treating patients with NPMSI with non-retained foreign body $(2,3)$, an invasive treatment comprising safe removal of foreign body and repair of injured structure is oftentimes recommended in those with retained foreign body.(4) NMPSI can be categorized into immediate and delayed types. Immediate spinal injury is caused by direct penetrating injury and vascular injury.(5) Delayed neurological deficit may be caused by CSF leakage, spinal cord herniation, retained foreign body, infection and edema. $(6,7)$ Since immediate injuries occurred before reaching medical cares, efforts should be paid to prevent delayed neurological deficits. Currently, there is no guideline on treating patients with NMPSI, particularly addressing issues on preventing delayed injuries mainly CSF leakage and spinal cord herniation, in other words, repairing dural defect. By presenting this case, we discuss and propose an algorithm for dural defect repair (Fig. 4). 


\section{Case Presentation}

This is a 51-year-old male construction worker with the past history of colon perforation status post right hemicolectomy. While working, he fell down from an altitude of six meters and landed on a plier placed on the floor vertically (Fig. 1A,B). At the emergency department, he was alert and oriented, with stable vital signs: $\mathrm{T}: 36.1^{\circ} \mathrm{C}, \mathrm{P}: 81 / \mathrm{min}, \mathrm{R}: 20 / \mathrm{min}, \mathrm{BP}: 149 / 99 \mathrm{mmHg}$. He complained of low back pain, bilateral extremities numbness and weakness. Physical examination showed smooth breathing sound, no distant heart sound, no Cullen's sign, no abdominal tenderness, and no deformity of extremities. Neurological examination revealed decreased muscle strength (grade 3/3) in bilateral lower extremities, paresthesia below knee and decrease deep tendon reflex of ankle jerk. There was normal anal sphincter tone. Lab data confirmed no anemia $(\mathrm{Hb}=15.4 \mathrm{~g} / \mathrm{dL})$, no renal or hepatic function impairment $(B U N=9.8 \mathrm{mg} / \mathrm{dL}$, creatinine $=0.86 \mathrm{mg} / \mathrm{dL}$ and $A L T=33 \mathrm{U} / \mathrm{L}$ ). A computed tomography showed a pair of pliers penetrating $\mathrm{L} 4$ lamina, spinal canal, through vertebral body and psoas muscle into retroperitoneal cavity with IVC indentation (Fig. 2). There was no contrast extravasation or bloody ascites in the peritoneal cavity.

Under the diagnosis of NMPSI with retained foreign body at lumbar level, the patient then underwent emergent combined surgery of trauma surgeon and neurosurgeon for the prevention of IVC bleeding upon foreign body removal. The patient was placed in three-quarter supine position (Fig. 1D). A paramedian laparotomy with transverse extension was done first to expose right retroperitoneal space after elevation of liver. The plier tip was palpated, confirming that the medial arm located at the lateral aspect of suprarenal IVC and the lateral arm located closely to the upper and lateral pole of right kidney (Fig. 1E). The IVC was intact, accompanying with no injury to renal pedicle artery and mild kidney abrasion. After affirmation that there was no active bleeding or major organ damage, the foreign body was removed cautiously from the back of the patient by neurosurgeon (Fig. 1D). There was CSF leakage and a simple stitch closure was made. After closure of abdominal wound, the patient was then placed in prone position. A midline incision was made and muscle was dissected to expose L3-L4 lamina. After laminectomy and bone chip removal, a through-and-through dural defect was found (Fig. $3 \mathrm{~A}$ ) and several adherent rootlets related to penetrating friction were seen at the margin of VDD. The VDD was tunneled to L3/4 disc space and packed with a piece of antibiotic-soaked gelfoam (Fig. 3B). We applied sling technique with $\mathrm{COOK}^{\circledR}$ artificial dura to cover the VDD after neurolysis and fixed it with 7-0 prolene (Fig. 3C). The dorsal dura defect (DDD) was closed primarily with watertight manner (Fig. 3D).

The patient's lower extremities muscle strength improved to grade 4 and his paresthesia of calf and toes gradually faded away. One week after the operation, he could urinate and ambulate without assistance. There was no positional headache, nausea, vomiting, neck pain or stiffness post-operatively, indicating no CSF leakage. The patient returned to normal life with mild sequelae of right toe numbness. A follow-up MRI showed patent CSF flow without pseudomeningocele (Fig. 4).

\section{Discussion}


Dorsal dura defects (DDD) can often be assessed and approached directly without further manipulation of intrathecal neural structures, therefore a primary repair for linear defect and an augmented duraplasty using various autograft or allograft dural substitutes are suitable (Fig. 5). In a series of 51 patients with spinal stab injury, $78 \%$ of whom underwent dorsal dura primary repair with only 2 patients (4\%) developed CSF leakage related to wound infection.(5)

While dorsal approach provides access to dorsal and lateral dura sac, it does not provide adequate access ventrally unless retracting or mobilizing of the neural structures which is often dangerous especially in cervical and thoracic level.(8) To prevent secondary injury to the spinal cord, two techniques of indirect repair have been reported in literature of $\mathrm{ISCH}$, which are duraplasty and widening of dural defect, respectively.(9) A comparison made by Saito et al showed more patients who underwent primary ventral dura closure had worsened neurological outcome compared to those underwent duraplasty or widening of the defect, suggesting an indirect repair is recommended than direct one in VDD.(10) A study of duraplasty after acute cervical laceration spinal cord injury in a rat model concluded that duraplasty was able to improve CSF flow by limiting meningeal fibrosis, reduce connective tissue formation, attenuate macrophage accumulation and progressive secondary injury, further supporting the use of duraplasty over widening of dural defect regarding choosing between indirect repair techniques.(11) An indirect duraplasty can further be classified into patch attachment and sling procedure.(12,13) Patch attachment requires manipulation of the neural structures for direct visualization of the defect edge to apply stitches or fibrin glue.(12) Meanwhile in sling procedure, dura graft is glided into the ventral space and fixed to bilateral dura wall without retraction of spinal cord.(14)

Based on above evidences, for repair of NMPSI with ventral dura defect, the risk of spinal cord mobilization should be of primary concern for choosing appropriate technique (Fig. 5). One thing makes the patients with NMPSI comparable to patients with ISCH is that a blunt injury with dural tissue loss in patients with NMPSI mimicking a spontaneous dura defect in ISCH. With sling procedure, even a larger defect can be repaired indirectly simply by dividing dentate ligament and designing sleeves for segmental roots to pass through. The use of sling procedure in NMPSI has never been reported to our knowledge, and a good outcome in our case demonstrates that sling procedure should be considered in managing patients with ventral dura defect.

For the choice of dural substitute, a great variety of grafts including autograft (ex: muscle fascia, fat), allograft (ex: cadaveric dural graft), xenograft (ex: bovine pericardium) and synthetic graft (ex: ePTFE dural substitute, Teflon, Gore-Tex).(12,15) Autograft was the first applied graft owning to its easy availability, but was limited by insufficient soft tissue and additional incisions. $(16,17)$ Allograft and xenograft are more flexible choices regarding to the customized sizes, but they still obtain the concern of immune reactivity and transmissible disease which includes the risk of prion disease. $(17,18)$ To avoid spinal cord damage during the insertion of dural graft, the material should be as thin and soft as possible, which is achievable in synthetic graft that can be less than $1 \mathrm{~mm}$. Synthetic graft is also associated with lower rates of wound infections, adhesions, CSF leaks and reoperation comparing to autograft in literature.(19) In the era of biodesign, various innovative grafts aiming biocompatibility, 
stronger sealing and better manipulation have been presented. The $\mathrm{COOK} \circledast$ dural graft we used is an example of using decellularized extracellular matrix to prevent immune response while still providing natural scaffold for cell growth.(20) Additional sealant to the duraplasty edge may be beneficial to preventing further CSF leakage.

\section{Conclusions}

In conclusion, managing patients of NMPSI with dura penetration, safe repair of dural defect is mandatory to prevent delayed neural injury. The location of defect (DDD vs. VDD), level of injury, and whether tissue loss or not, are practical determinants for choosing an appropriate method of dura repair. An indirect repair with sling technique is an easily adapted and effective surgical technique for traumatic VDD.

\section{Abbreviations}

-NMPSI: non-missile penetrating spinal injuries

-CSF: cerebrospinal fluid

-VDD: ventral dural defect

-DDD: dorsal dural defect

-ISCH: idiopathic spinal cord herniation

-IVC: inferior vena cava

\section{Declarations}

\section{-Ethics approval and consent to participate:}

Approval was obtained from the local ethics committee.

\section{-Consent for publication:}

The patient has consented to the submission of the case report for submission to the journal.

\section{-Availability of data and materials:}

Not applicable 


\section{-Competing interests:}

The authors declare that they have no competing interests

\section{-Funding:}

Not applicable

\section{-Authors' contributions:}

KTC performed the operation and conceived the abstract of the case report. CTW provided clinical experience and suggestion to the operation. TWC and YYC review related articles and composed the manuscript. All authors read and approved the final manuscript.

\section{-Acknowledgements:}

Nil

\section{References}

1. Wallace DJ, Sy C, Peitz G, Grandhi R. Management of non-missile penetrating spinal injury. Neurosurg Rev. 2019;42(4):791-8.

2. McCunniff PT, Ramey JS, Scott ML, Roach MJ, Vallier HA, Moore TA, et al. Operative Versus Nonoperative Management of Civilian Gunshot Wounds to the Spinal Cord: Novel Use of the Functional Independence Measure for Validated Outcomes. World Neurosurg. 2017;106:240-6.

3. Klimo P, Jr., Ragel BT, Rosner M, Gluf W, McCafferty R. Can surgery improve neurological function in penetrating spinal injury? A review of the military and civilian literature and treatment recommendations for military neurosurgeons. Neurosurg Focus. 2010;28(5):E4.

4. Simşek O, Kilincer C, Sunar H, Hamamcioğlu MK, Canbaz S, Cobanoğlu S, et al. Surgical management of combined stab injury of the spinal cord and the aorta--case report. Neurol Med Chir (Tokyo). 2004;44(5):263-5.

5. Enicker B, Gonya S, Hardcastle TC. Spinal stab injury with retained knife blades: 51 Consecutive patients managed at a regional referral unit. Injury. 2015;46(9):1726-33.

6. Eltoukhy M, Gkolemis C. Late-Onset Post-Traumatic Spinal Cord Herniation as a Rare and Overlooked Cause of Late Neurologic Deterioration After Penetrating Injury to the Thoracic Spine: A Case Report and Review of the Literature. World Neurosurg. 2020;142:408-12.

7. Peacock WJ, Shrosbree RD, Key AG. A review of 450 stabwounds of the spinal cord. S Afr Med J. 1977;51(26):961-4. 
8. Sasani M, Ozer AF, Vural M, Sarioglu AC. Idiopathic spinal cord herniation: case report and review of the literature. J Spinal Cord Med. 2009;32(1):86-94.

9. Randhawa PS, Roark C, Case D, Seinfeld J. Idiopathic Spinal Cord Herniation Associated With a Thoracic Disc Herniation: Case Report, Surgical Video, and Literature Review. Clin Spine Surg. 2020;33(6):222-9.

10. Saito T, Anamizu Y, Nakamura K, Seichi A. Case of idiopathic thoracic spinal cord herniation with a chronic history: a case report and review of the literature. J Orthop Sci. 2004;9(1):94-8.

11. Iannotti C, Zhang YP, Shields LB, Han Y, Burke DA, Xu XM, et al. Dural repair reduces connective tissue scar invasion and cystic cavity formation after acute spinal cord laceration injury in adult rats. $J$ Neurotrauma. 2006;23(6):853-65.

12. Akutsu H, Takada T, Nakai K, Tsuda K, Sakane M, Aita I, et al. Surgical technique for idiopathic spinal cord herniation: the Hammock method. Technical note. Neurol Med Chir (Tokyo). 2012;52(4):238-42.

13. Herring EZ, Shin JH, Nagel SJ, Krishnaney AA. Novel Strategy of Ventral Dural Repair for Idiopathic Thoracic Spinal Cord Herniation: Report of Outcomes and Review of Techniques. Oper Neurosurg (Hagerstown). 2019;17(1):21-31.

14. Batzdorf U, Holly LT. Idiopathic thoracic spinal cord herniation: report of 10 patients and description of surgical approach. J Spinal Disord Tech. 2012;25(3):157-62.

15. Payer M, Zumsteg D, De Tribolet N, Wetzel S. Surgical management of thoracic idiopathic spinal cord herniation. Technical case report and review. Acta Neurochir (Wien). 2016;158(8):1579-82.

16. Bi X, Liu B, Mao Z, Wang C, Dunne N, Fan Y, et al. Applications of materials for dural reconstruction in pre-clinical and clinical studies: Advantages and drawbacks, efficacy, and selections. Materials Science and Engineering: C. 2020;117.

17. Warren WL, Medary MB, Dureza CD, Bellotte JB, Flannagan PP, Oh MY, et al. Dural repair using acellular human dermis: experience with 200 cases: technique assessment. Neurosurgery. 2000;46(6):1391-6.

18. Alleyne CH, Barrow DL. Immune response in hosts with cadaveric dural grafts. 1994;81(4):610.

19. Abla AA, Link T, Fusco D, Wilson DA, Sonntag VK. Comparison of dural grafts in Chiari decompression surgery: Review of the literature. J Craniovertebr Junction Spine. 2010;1(1):29-37.

20. Hodde J, Janis A, Ernst D, Zopf D, Sherman D, Johnson C. Effects of sterilization on an extracellular matrix scaffold: part I. Composition and matrix architecture. J Mater Sci Mater Med. 2007;18(4):53743.

\section{Figures}




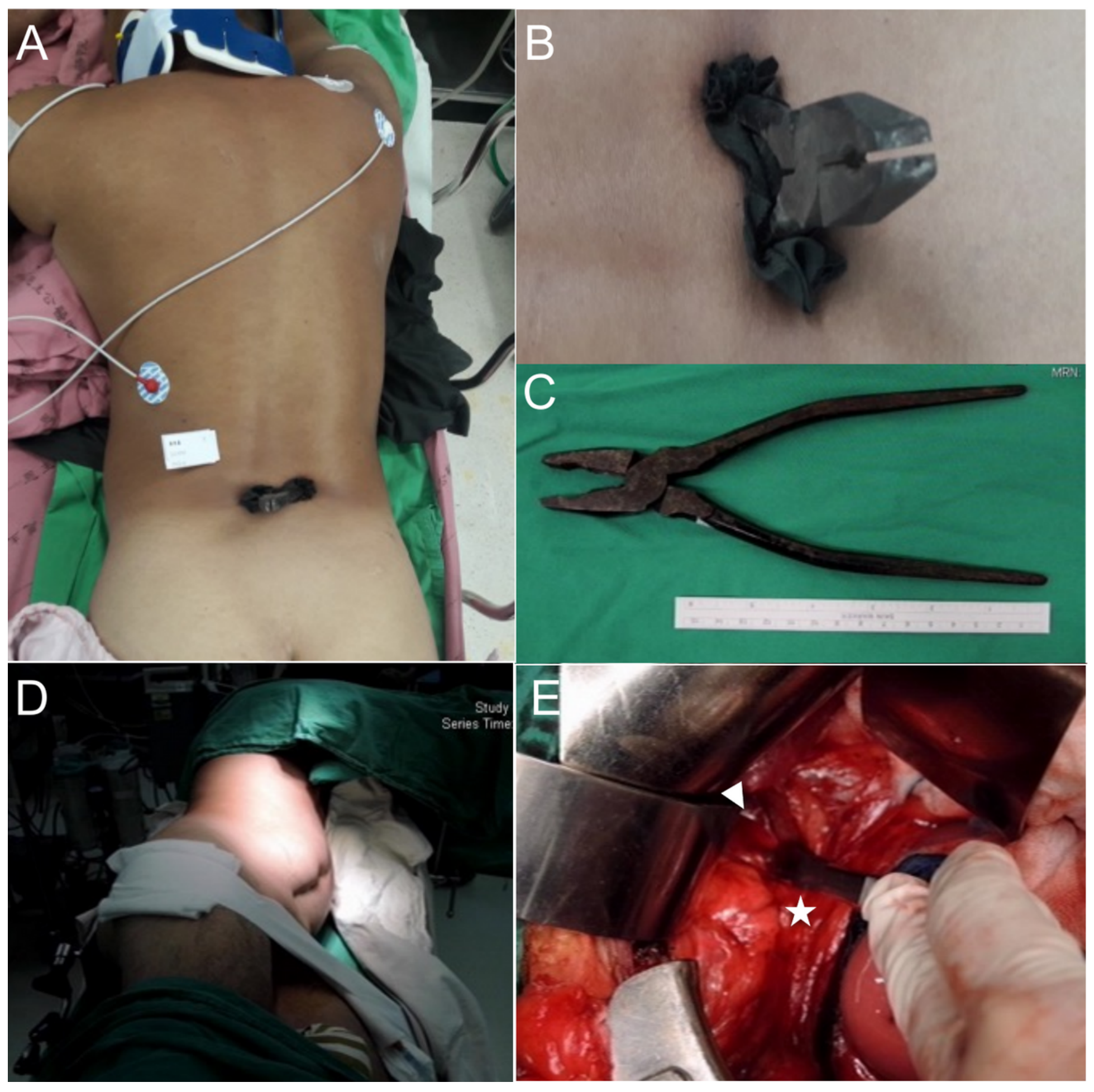

Figure 1

Pre- and intra-operative pictures. (A) A pair of pliers penetrated into the patient from behind at lower lumbar area in the midline. (B) A closer look of the pilers and the dragged fragment of his clothes. (C) A total $14 \mathrm{~cm}$ long handle was inside the patient's body. (D) Intraoperatively before laparotomy, a left decubitus position was prepared. (E) Direct vision of the handle tip of pliers (arrowhead) after we opened the retroperitonium cavity and retracted inferior vena cava (asterisk) away. 


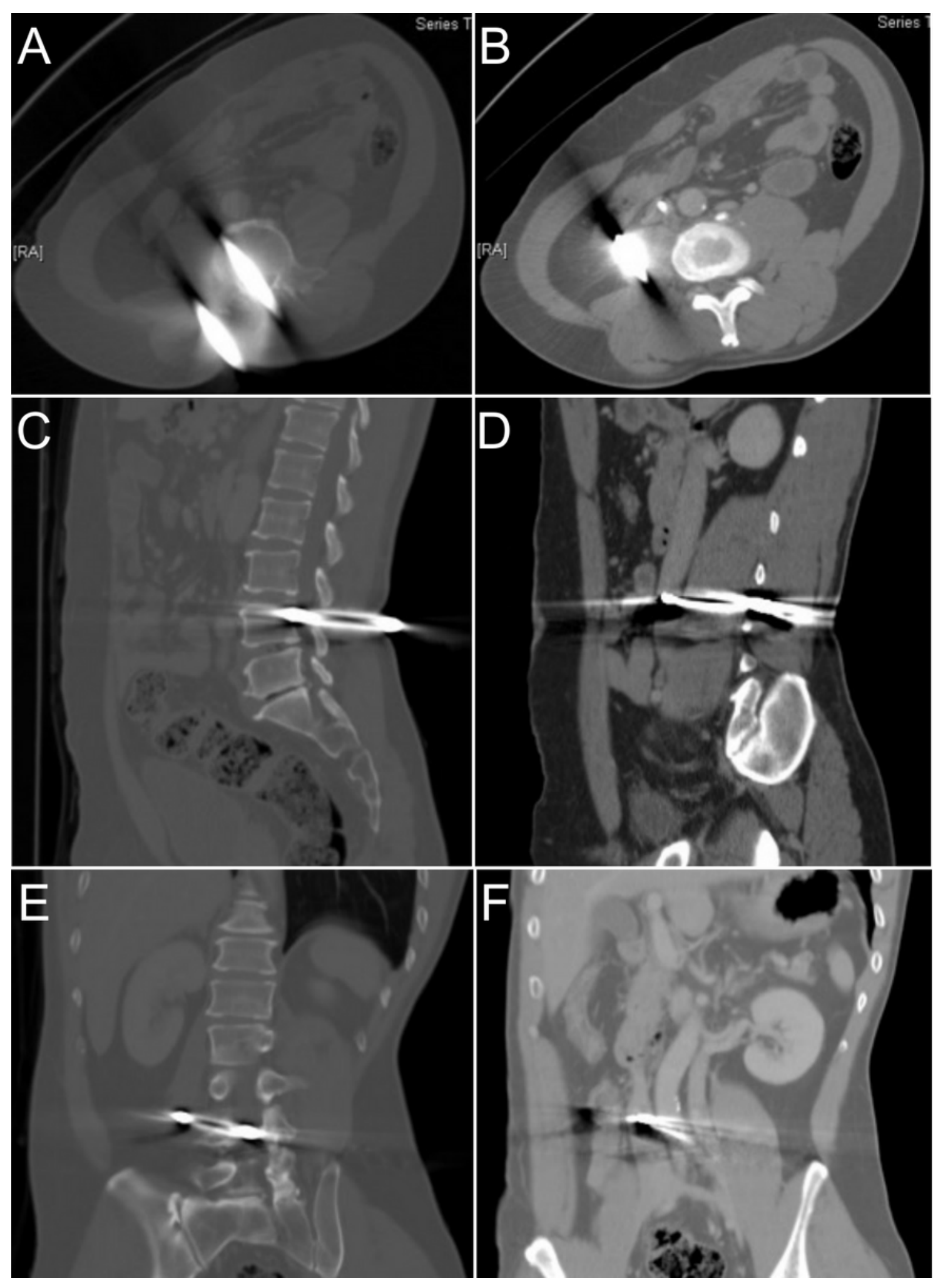

Figure 2

Preoperative abdominal CT. A pair of pliers penetrated L4 lamina, spinal canal and vertebral body through right psoas muscle into retroperitoneal cavity was shown in axial $(A, B)$, sagittal $(C, D)$ and coronal $(E, F)$ view. Note the inferior vena cava was pushed aside by the tip of pliers $(B, F)$. 


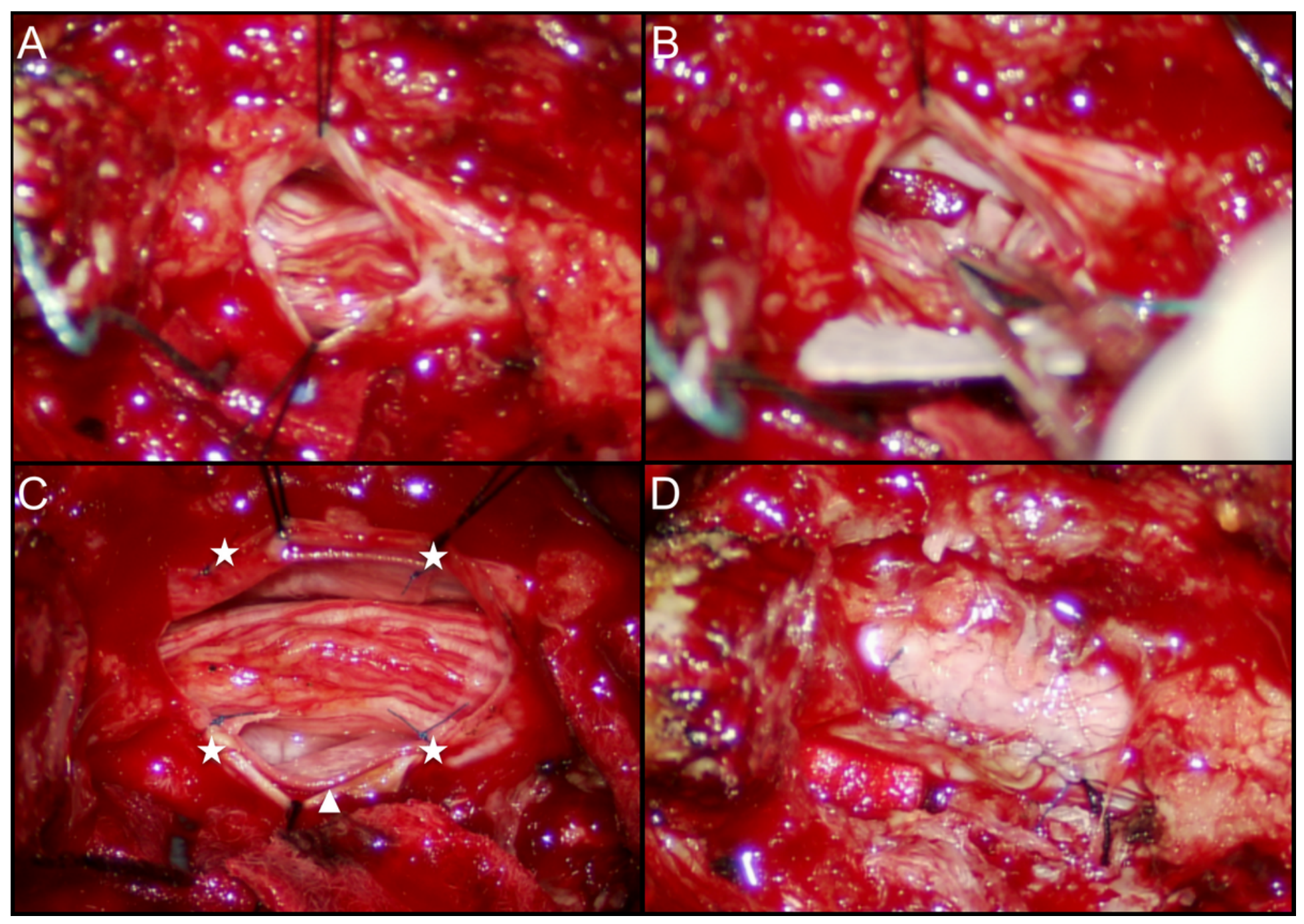

Figure 3

Intraoperative microscopic pictures of dura repair using sling technique. (A) After partial L3 and L4 laminectomy, a traumatic durotomy was found and it was extended rostrally and caudally for better inspection and management of intrathecal damage. (B) A ventral dural defect was packed with gelfoam for hemostasis and all injured rootlets were gently reduced into intradural cavity. (C) Sling technique was selected to repair the ventral dural defect by using artificial dural graft (arrowhead), which was sutured on the ventral (not shown) and the dorsal side (asterisks). (D) A final look of the fully-expanded thecal sac after primary repair of traumatic dural defect. 


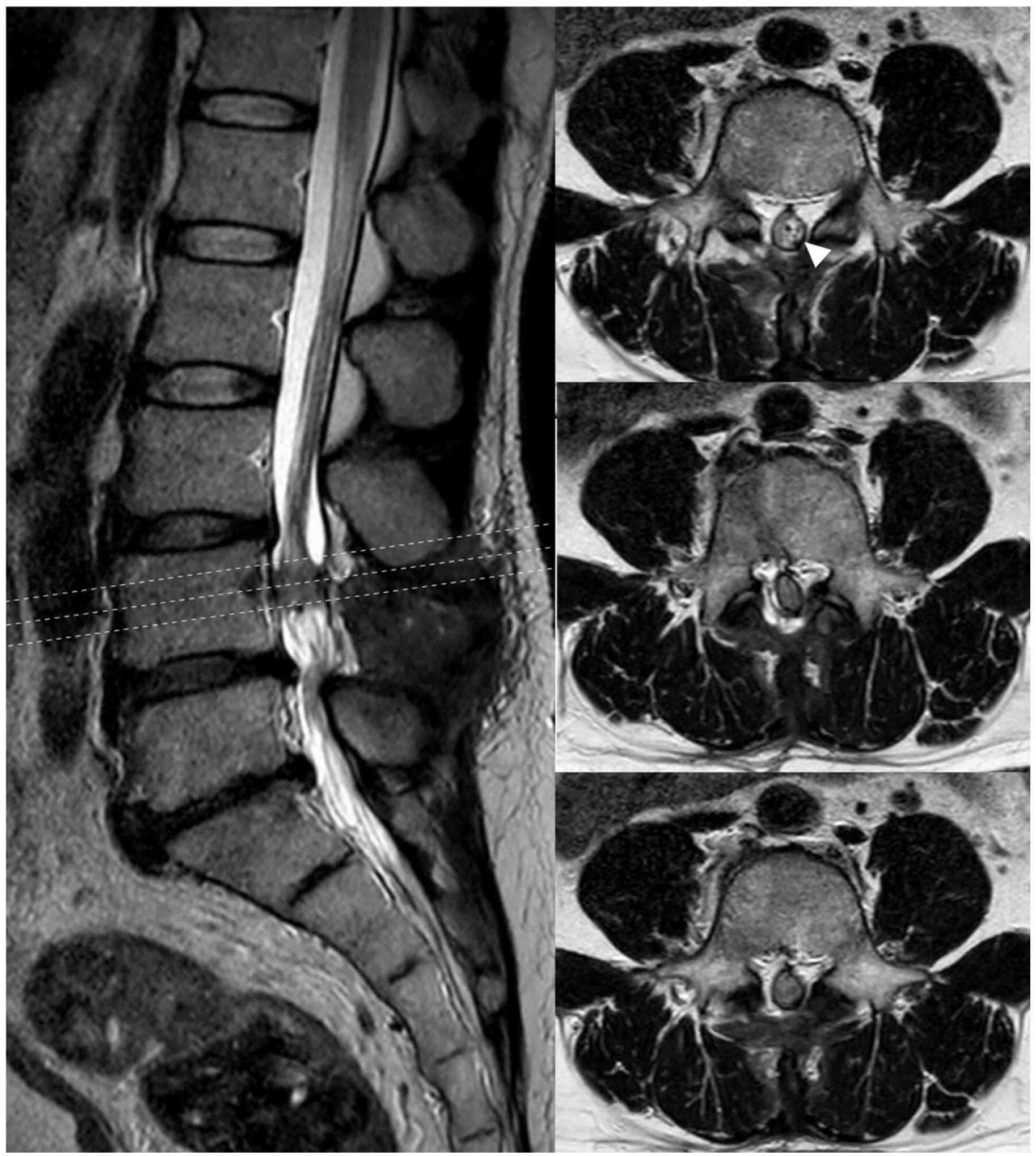

Figure 4

Postoperative 6 month MRI of Lumbar spine showed good coverage of artificial dural graft (arrowhead) circumferentially. There was no pseudomeningoceal. 


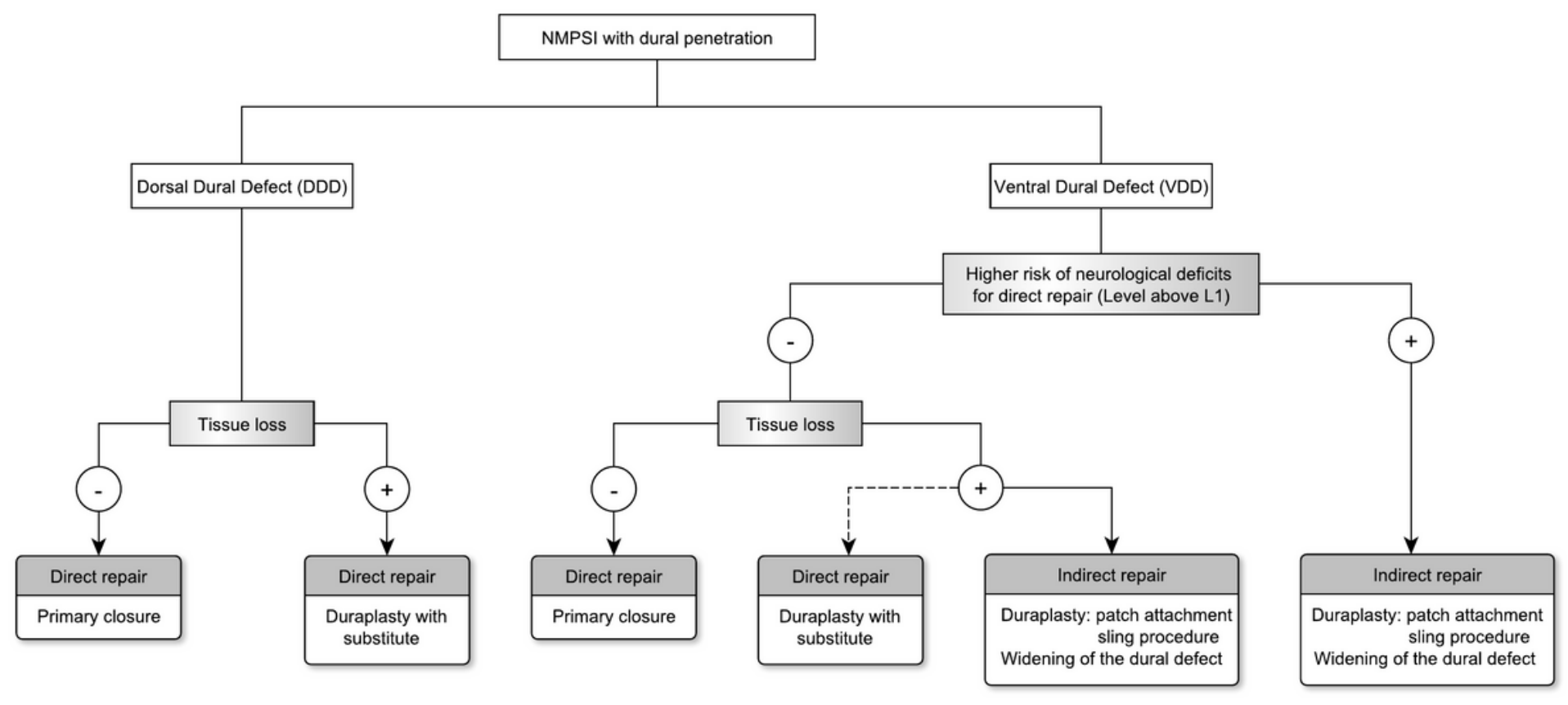

\section{Figure 5}

Dural defect in NMPSI can be categorized into VDD(ventral dural defect) and DDD(dorsal dural defect). In VDD with higher risk of neurological deficits or tissue loss, indirect repair is recommended to minimize secondary injury. In DDD and VDD without tissue loss, direct repair is indicated. Direct repair includes primary closure and duraplasty with substitute; indirect repair includes sling procedure, patch attachment and widening of dural defect. 